Karageorghis, C. I. (2014). Run to the Beat: Sport and music for the masses. Sport in Society, 16, 443-447. doi:10.1080/17430437.2013.796619

\title{
Run to the Beat: sport and music for the masses
}

\section{Costas I. Karageorghis}

School of Sport and Education, Brunel University, London, UK

Run to the Beat is a half marathon event that is accompanied by live and pre-recorded music. The author was involved with the event as lead consultant in the period 20072010. This case study examines the genesis of the event, the science on which it was predicated and how it was received by participating runners and the media. The primary driver for the event was the 2007 ban on personal listening devices by the International Amateur Athletics Federation, which outraged recreational runners. There is a corpus of work (approximately 100 studies) that has examined the effects of music in exercise and sport. The most conclusive findings from this work are that music reduces perceived exertion at low-to-moderate exercise intensities and, if well selected, enhances affect at all intensities. The Run to the Beat events received mixed reviews from participants, but were generally positively presented by the international media. The event continues today on an annual basis in London, UK and Basel, Switzerland.

\section{'Run to the rhythm, run to the beat, keep your feet moving, and pound that street!'}

The cultural pursuits of playing and listening to music as well as moving in synchrony with it may be as old as civilisation itself. Music pervades so many aspects of our daily lives entertainment, relaxation, religious rites, car driving, physical activity - that it would be hard to imagine what life would be like in its absence. In the domain of physical activity, musically accompanied exercise modalities such as aerobic dance classes developed rapidly in the 1970s and 1980s. This development transcended group-based exercise and spread rapidly to individual forms of exercise when personal listening devices such as Nike's Personal Sport Audio ${ }^{\mathrm{TM}}$ were marketed at the turn of the millennium. 
Over the last two decades, music has been integrated into many large scale sporting events; such infusions of 'showbiz razzamatazz' are lauded by some but reviled by traditionalists. Since Apple's Steve Jobs envisioned the Pod $^{\mathrm{TM}}$, there has been an explosion in music use by athletes during training and prior to competition, while countless millions of exercise participants use music to enhance the experience of their daily workout. New technology allows exercise participants to create their own 'listening bubble'.

We have the freedom, at the touch of a button, to formulate playlists in accordance with our musical predilections; something that was unimaginable during my teenage years when vinyl was still very much de rigueur. Thousands of tracks can be stored in a headphone set weighing just 100 grams and it is no exaggeration to say that virtually everyone in Western society below the age of 50 owns a personal music playing device. The sophistication of the technology grows apace; for example, Nike and Apple now manufacture a device (the Nike Plus) that enables runners to link their shoes to their iPod Nano so as to give updates on pace, mileage and calories expended. Playlists are also commonly designed with specific heart rates and stride frequencies in mind.

I began to work in the area of music and sport/physical activity in the early 1990s and since that time, my main intention has been to develop a systematic body of work to assist researchers, exercise practitioners and exercise participants in the application of music. I am not an advocate for the music industry; I often document instances in which music can have a detrimental effect on physical performance or mental state. ${ }^{2}$ Rather I am interested in examining in an objective way the contingencies that underlie the use of music and the complex interactions between the person, the situation and the task that determine emotional and behavioural responses to it. My interest has evolved from laboratory investigations of simple motoric tasks such as grip strength, to an examination of complex behaviours in the 
wider realm of sport and exercise. In recent years, I have also developed an interest in music use during driving and in physiotherapy rehabilitation.

Owing to the nature of my work as a researcher-practitioner, I have been involved in several industrial projects and these have included collaborations with Nike Inc., DavidLloyd Leisure, Red Bull, Sony and Speedo. One of the largest and most impactful of these collaborations concerned a project for the International Management Group (IMG) that came to be known as Run to the Beat, with which I was involved as lead consultant in the period 2007-10. In this brief case study I will detail the genesis of Run to the Beat, the scientific work that underlies the event and present a critical evaluation of how the event has been received both by its participants and the international media.

\section{Part 1: The Genesis of Run to the Beat}

The organisers of mass participation running events have been deliberating for more than a decade over whether participants should be permitted to use personal listening players. The devices are deemed to pose a safety risk as runners purportedly become so intoxicated by the music that they bump into one another, miss instructions from race marshals or, in extreme cases, even get run over. The International Amateur Athletics Federation banned the use of personal listening devices in championship events in the autumn of 2006. Their reason for doing so was that they did not want athletes to receive information via radio about the whereabouts of their rivals. Nowadays when I visit track and field events, I notice that officials do not allow athletes to bring their personal listening devices anywhere near the track; this is often the cause of considerable disquiet.

In 2007, USA Track and Field published the following new rule for championship races and for those participants who wished to pursue prize money: 
The visible possession or use by athletes of video or audio cassette recorders or players, TVs, CD or DVD players, radio transmitters or receivers, mobile phones, computers, or any similar devices in the competition area shall not be permitted. $^{3}$

Not wanting to incur the wrath of USA Track and Field, the organisers of the 2007 New York Marathon banned the use of personal listening devices, which prompted vociferous objections from competitors:

'I'm going to wear mine. I have got to. It's very important to me because I get really bored,' said Annie Purcell, a doctor, who likes to listen to Snoop Dogg, as she picked up her race number yesterday in New York. 'It would be really bad if they were to enforce the ban'. 4

The ban also stimulated an interesting media debate that kept me occupied for several weeks, ${ }^{5}$ and led to a lengthy feature on music in exercise in The New York Times. ${ }^{6}$ The banning of $i P o d s$ and other mp3 devices in mass participation events is almost impossible to enforce without a dedicated 'music police', therefore many runners chose to openly defy the ban, prompting complaints from their fellow competitors. There was also an economic motive underlying the ban: insurance companies threatened to raise the premiums paid by race organisers if the iPod ban was not enforced.

There is a trend in some long-established mass-participation events, such as the Philadelphia Marathon (USA) and the Great North Run (England), to place live bands on the course to give the runners a psychological boost. Such events showcase local rock bands or even school orchestras and the music played is selected in a somewhat arbitrary manner. During the present decade, however, it appears that the organisers of mass participations running events - such as the Philadelphia Marathon - are beginning to take a more systematic 
approach to music delivery and the experience of the spectators. The Philadelphia race of 2011 had more than 25 'cheer zones' at which spectators were encouraged to congregate and were even offered free hot chocolate.

Given the fallout from the 2007 New York Marathon, executives from the International Management Group's (IMG) UK office began to consider the possibility of launching a half marathon event in London with live musical accompaniment. They had identified a clear gap in the market - London did not have a half marathon event and there were certainly no comparable events internationally in which live bands lined the entire course. IMG had a track record of hosting other mass participation events in the London area such as the hugely successful London Duathlon (running followed by cycling) in the picturesque surroundings of Richmond Park.

In early autumn 2007, the then managing director of mass participation sports at IMG, Nick Rusling, stumbled across some of my research on an Australian internet site. ${ }^{7} \mathrm{He}$ thought that the proposed event - which had the working title London's Half-Marathon to Music - could have a scientific component, with the music selected according to objective principles in order to boost the runners' performance. There was a slightly amusing twist to how we forged a working relationship. Rusling assumed that I was based in Australia and emailed me in the hope that we might arrange an early morning conference call. It transpired that, at the time, I was living in the same road as the IMG UK offices in Chiswick, west London. Thus, it was not long before a contract was drawn between IMG and my institution. Thereafter, we began to plan the inaugural Run to the Beat event which took place in the London Borough of Greenwich on Sunday, 5 October 2008.

The route for the London events starts and finishes at The O2 Arena (see Figure 1). Runners proceed along the river towards the Thames Barrier, past Firepower - The Royal Artillery Museum, the Royal Artillery Barracks and Greenwich Park. The main stage is 
located next to the start-finish line and music is played at various stages along the route; the headline acts perform on the main stage. The title sponsors of the inaugural event were Sony Ericsson: an association that remained intact for two years. The event also developed an affiliation with City Showcase, a London-based, not-for-profit organisation that, since 2003, has worked to identify and develop new, unsigned artists through a combination of live performance opportunities, industry networking sessions and master-classes. City Showcase provided the mainstay of the live musical accompaniment in each of the London Run to the Beat events. My personal relationship with the City Showcase management was cordial, but our professional relationship was characterised by considerable tension: They wanted to promote original compositions by unsigned London artists while I wanted to determine precisely what runners would hear on the course, in line with the scientific premise of the event.

\section{*** INSERT FIGURE 1 AROUND HERE $* * *$}

Throughout my tenure, the event's official charity sponsor was Leukaemia and Lymphoma Research, the principal organisation funding blood-cancer research in the UK. In 2010, an exciting development took place in the rollout of the event to mainland Europe. The Swiss incarnation of Run to the Beat took place in Basel on 12 September 2010, on a far smaller scale than the London event, and featured just five 'hotspots' along the route with live bands. The city of Basel was chosen due to its affinity to sports, music and culture and also because it was deemed that it would attract runners from both France and Germany. I was not involved as a consultant to the Basel event, only the London events that were held on the Sundays of 5 October 2008, 27 September 2009 and 26 September 2010.

Most of my work was completed in the months preceding each event as I was the IMG spokesperson at press conferences, launch events and media days. There were specific media days for TV companies with a documentary about the event broadcast each year on 
Channel 4 (UK) as well as numerous ad hoc broadcasts such as an hour-long documentary for Globo TV (Brazil). I also advised several journalists who were taking part in the event and devised playlists for pre-recorded music stations and some of the live acts. Moreover, I contributed scientific information for the event website and selected material for three compilations of running music that were released in tandem with the event each year.

\section{Part 2: The Scientific Premise of Run to the Beat}

The essential premise underlying Run to the Beat was that music selections should be made to match the physiological demands of the event and the demographic profile of participants, which was determined using data generated by the event's website. ${ }^{8}$ In the following paragraphs, I present the theoretical background and empirical evidence underlying the music selections that I made.

\section{Conceptual approaches to the use of music in the exercise domain}

The notion of motivational music has been key to the development of conceptual models of musical response in exercise. Motivational music was defined in terms of its effects: reduced perceptions of exertion, arousal regulation and improved affect. ${ }^{9}$ Over time, this list of positive consequences grew to include the attainment of flow state, enhanced skill acquisition and ergogenic effects. ${ }^{10} \mathrm{~A}$ conceptual model depicting the antecedents, intermediaries and consequences of motivational music use appears in Figure 2. The essential tenet of the conceptual model is that the personal characteristics of the exerciser/athlete coupled with situational characteristics inform the optimal choice of musical accompaniment.

\section{*** INSERT FIGURE 2 AROUND HERE $* * *$}

My colleagues and I developed an instrument to rate the motivational effects of music - the Brunel Music Rating Inventory (BMRI), ${ }^{11}$ which was refined in 2006 to enhance its 
psychometric properties and applicability to exercise participants (BMRI-2). ${ }^{12}$ In selecting music to accompany the Run to the Beat events, I used the BMRI-2 to rate pools of possible music selections according to their motivational qualities. Members of the rating panels used were representative of those taking part in the event in terms of ethnicity, gender breakdown and age profile.

In addition to the objective ratings, I incorporated a variety of subjective criteria based on extant theory. ${ }^{13}$ I selected music with lyrics that contained affirmations of movement, particularly running, and positive statements relating to the surmounting of obstacles (e.g., 'Run To You' by Bryan Adams and ‘Ain’t No Mountain High Enough' by Diana Ross and the Supremes). My co-workers and I also sought to include music which bore extra-musical associations relating to aspects of popular culture relevant to sport, running, or the Olympic movement (e.g., Vangelis's 'Chariots Of Fire'). In some cases, the associations went beyond sport to touch on themes of heroism and fortitude - the Royal Artillery Band played a selection of rousing themes which included those of the Superman and Indiana Jones motion picture franchises. While the demographic constituency of the participants was dealt with in part by using representative groups of raters, for the 2009 event, I worked closely with sponsors Sony Ericsson to foreground the cultural positioning of the soundtrack by segmenting it into four meta-categories: pop, rock, urban and dance. This segmentation was highlighted in the marketing material connected to the event. ${ }^{14}$

A final consideration was variety among the selections. Together with senior colleague Professor Craig Sharp and my then doctoral student David-Lee Priest, I published a study in 2004 based on data that we had collected from 29 David-Lloyd Leisure health clubs across the United Kingdom. ${ }^{15}$ The findings indicated that variety in the musical programme is of paramount concern for exercisers. Hence, I sought to ensure that the music programme was varied in terms of idiom (e.g., pop, dance, rock, urban), artist and era of release. This 
strategy was aimed at maximizing the appeal of the programme across a diverse group of listeners and minimizing any deleterious effects caused by a succession of similar songs which a certain group of participants may have disliked. The 'battle of the genres' strategy also developed considerable media interest in the event. ${ }^{16}$ We were able to obtain information from entrants pertaining to their idiomatic preferences through an online interface. In addition, data were collected at the inaugural Run to the Beat event, which indicated the four most popular or 'super-ordinate' idioms.

\section{Effects of music in the exercise domain}

During submaximal exercise, music can narrow attention and this, in turn, diverts the mind from sensations of fatigue. This diversionary technique, known as dissociation, serves to lower perceptions of effort by up to $12 \%$ during treadmill running. ${ }^{17}$ This effect holds for low and moderate exercise intensities only; at high intensities, perceptions of fatigue override the impact of music, because attentional processes are dominated by physiological feedback such as respiration rate and the accumulation of lactic acid in the musculature. ${ }^{18}$

Although music does not reduce the perception of effort during high intensity exercise, it does improve the experience thereof: It can make a hard training session enjoyable by shaping how the mind interprets symptoms of fatigue. This was borne out in a recent study conducted by my co-workers and me. ${ }^{19} \mathrm{We}$ found that motivational music reduced perceptions of exertion and improved feeling states at the outset of a treadmill walk to exhaustion. We used the Feeling Scale ${ }^{20}$ that assesses the positivity or negativity of participants' affective states. In the latter stages of the walk, when participants began to experience considerable fatigue, the motivational music selection failed to impact upon their ratings of perceived exertion yet promoted more positive feeling states. Essentially, during a hard session, music has limited power to influence what the athlete feels, but if well selected, 
it does have considerable leverage on how the athlete feels; it can 'colour' the interpretation of fatigue-related symptoms.

Music alters psychological and physiological arousal and can therefore be used prior to competition or training as a stimulant, or as a sedative to assuage anxiety. ${ }^{21}$ Music thus facilitates arousal regulation and allows us to foster an optimal mindset. Pre-task music has been successfully used as a stimulant prior to both strength ${ }^{22}$ and muscular endurance ${ }^{23}$ tasks. Music can also exert a stimulative effect when used during an exercise task.

A prominent strand of our work has investigated the relationship between exercise heart-rate and one's preference for music tempo. ${ }^{24}$ Whereas a positive linear relationship was hypothesised in previous work, ${ }^{25}$ we found a more intricate pattern characterised by two distinct inflection points (a cubic relationship; see Figure 3) ${ }^{26}$ In essence, exercisers working over the entire range of intensities we have assessed (e.g., 40-90\% maximum heart rate reserve) exhibit a preference for music in the narrow tempo range of 125-140 beats per minute (bpm). For this reason, musical tempo was an essential criterion in the selection process; it is also, along with intensity (loudness), the easiest component of music to manipulate. ${ }^{27}$ The tempi selected rose gradually during the course of the run in broad agreement with the curve depicted in Figure 3. For example, at the 1-mile stage the tempo chosen was approximately $125 \mathrm{bpm}$ whereas as the runners approached the finish, the plan was that they would encounter faster, more arousing music (approx. $140 \mathrm{bpm}$ ).

\section{*** INSERT FIGURE 3 AROUND HERE ***}

Research has consistently shown that the synchronisation of music with repetitive exercise is associated with increased levels of work output. ${ }^{28}$ This applies to such activities as rowing, cycling and cross-country skiing while the supporting evidence is particularly strong in running. ${ }^{29}$ Musical tempo can regulate movement and thus aid performance. ${ }^{30}$ In our 
recent study using a treadmill-walking task, we found that motivational music led to a $15 \%$ increase in endurance before the point of voluntary exhaustion, when compared to a no-music control condition. ${ }^{31}$ Synchronising movements with music also enables athletes to perform more efficiently, again resulting in greater endurance. In another recent study, participants who cycled in time to music found that they required $7 \%$ less oxygen to do the same work as compared to cycling with background (asynchronous) music. ${ }^{32}$ When preparing for Run to the Beat, we found there was an inherent difficulty in selecting music as a "pacemaker" for runners to synchronise themselves to: The event incorporates a vast range of running ability and body-types as well as varying topography which leads to a huge variability in stride-rate frequency. Nevertheless, I aimed to select music with regular rhythmic qualities rather than an irregular or highly syncopated rhythm.

In a variety of exercise modalities, music has been shown to promote an ergogenic effect. This effect may take the form of an increase in strength output, ${ }^{33}$ aerobic endurance ${ }^{34}$ or work rate. ${ }^{35}$ Such findings were considered in depth as I approached the music selection for the event with the view of enhancing participants' work rate and endurance. In practice, this meant that the musical pieces with the highest motivational quotients (as rated by the BMRI-2) were delivered in the last 3 miles of the event when participants would be experiencing pronounced fatigue.

The demographic information fed back from the Run to the Beat website indicated that, in complete contrast to most mass participation events, the participants were predominantly female (2:3 male-female ratio). This imbalance in itself may suggest that the concept of exercise-to-music is particularly attractive to women: whether by virtue of the culture that surrounds it or the way women are brought up. Reasons advanced in extant literature to support the hypothesis that women are likely to derive greater benefit from music, include greater exposure to dance music and movement-to-music during their 
formative years, ${ }^{36}$ and the greater desire they demonstrate to engage in dance-related activity. $^{37}$

Research findings have pointed towards the existence of minor gender differences in terms of responses to musical rhythm. ${ }^{38}$ Experimental work using circuit-style repetitive exercise (e.g., sit-ups and calf raises) has shown that men may derive less ergogenic benefit from synchronous music than women. ${ }^{39}$ Other studies have shown that women are more likely to endure for a longer period in response to motivating music, ${ }^{40}$ whereas qualitative work $^{41}$ indicates that women may place more importance on the rhythmical qualities of music in the exercise context.

\section{Part 3: Evaluation of the London Run to the Beat events (2008-10)}

\section{Participation}

In the first two events (2008 and 2009), data provided online indicated that, for the majority of participants, it was their first half marathon. In 2008, organisational and transport problems - of which more later - coupled with inclement weather meant that only 7,252 of those $12,000+$ who entered the event actually completed it. In 2009 , this figure rose to some 9,082 runners from a similar number of entrants. After overcoming initial teething problems, the event seemed to gather momentum in the final year of my association with it: over 11,000 crossed the start line from a reputed $14,000+$ entrants. $^{42}$

Whereas the inaugural event was won by John McFarlane (Thames Hare and Hounds) in a relatively pedestrian time of $1 \mathrm{hr} 10 \mathrm{~min}$ and $12 \mathrm{~s}$, the second and third years of the race were patronised by a better class of athlete entirely. In 2009, the men's race was won by wellknown Kenyan Ezekiel Cherop in a far superior time of $1 \mathrm{hr}$ and $3 \mathrm{~min}$ dead. This high standard was maintained in 2010, which saw the men's race completed in a similar time and 
Kenyan Hellen Jemutai setting a new best in the women's race of $1 \mathrm{hr} 14 \mathrm{~min}$ and $7 \mathrm{~s}$. John McFarlane, winner of the 2008 event, posted a revealing comment to an online runners' forum on 28 September 2009:

I must admit I was disappointed when I turned up on the day to find four Kenyans warming up. These guys weren't on the startlist, and with hindsight I should have phoned to check on Friday, which to be fair, I think some of the Brits did. Hence no-one else turned up. To my mind it did spoil the race, and okay, 70 mins is not quick for a half, but I think it deters Brits if Kenyans turn up to these races with prize money at the last minute. I won good money last year for winning this race in a slow time, and it probably won't happen again, but it's not like British athletes earn a lot of cash. With hindsight I wish I'd done Windsor. ${ }^{43}$

I interviewed the Kenyan athletes immediately after the 2009 event and they had precious little to say about the musical aspect of the half marathon other than it was 'very nice!' This was unsurprising given that research has shown elite distance runners tend to be associators who focus inwardly on regulating their bodies ${ }^{44}$ and that recreational runners are far more likely to benefit from musical accompaniment than those who are highly trained. ${ }^{45}$

\section{Organisation}

While IMG had considerable experience of staging mass-participation events prior to Run to the Beat, the event did not pass without a few organisational glitches. The 2008 race got the series off to a bad start as heavy rain conspired with a closure of the local London Underground network to result in a poor reaction from entrants, especially those from the road-running community. The problems were expressed by journalist Claire Soares: 
Sunday brought torrential rain and a suspension of the Jubilee Line that was supposed to get people to the start at the $\mathrm{O} 2$ dome. And the chaos meant that some bands didn't make it to their designated spots on the route, and those that did battled rain-induced hitches.... The ska-rap-rock combo Imperial Leisure did make it to the main stage by the starting line, which was lucky, given that their opening riff was replacing the traditional starting gun. However, the jumping up and down my running mate Mindy and I began to do at this point may well have been a reaction to standing in the pouring rain for half an hour. $^{46}$

The organisers did their best to mitigate the problems evident in the local transport system by delaying the start; nonetheless, many thousands of athletes had already warmed up and were in the holding pens ready to go at $10.00 \mathrm{am}$. Soares' views were echoed, albeit in a more upbeat style, by forum contributor Nerina Chatterley:

The rain was relentless and the organisation a bit wonky. But the crowds were brill and the vibe in the holding pens was great. I think adverse weather conditions give everyone something in common to deal with. Music was a bit, actually a lot, rubbish so they may want to rename this next year and ditch the music theme. ${ }^{47}$

Due to its location on a peninsula at the nape of a sharp bend in the Thames, the $\mathrm{O} 2$ arena is not particularly accessible by road transport. The transport problems were blighted by the fact that the line closure was part of an extensively advertised series of engineering works of which the event organisers were apparently unaware. While matters improved markedly in 2009 and 2010, experienced runners continued to heavily criticise organisational 
aspects of the event; the posts on a 2010 Runner's World forum bearing generous evidence of this. $^{48}$

A consensus seems to have emerged in that, in stark opposition to the marketed concept and raison d'être of the event, the music provision had proven to be consistently weak, inappropriate or even non-existent. Indeed, an oft-cited viewpoint among those within the running community was that the established Great North Run, which is normally run on the preceding weekend, provides a superior musical accompaniment while also being impeccably organised and representing value for entrants. The positive reviews of Run to the Beat were generated predominantly by fun runners, particularly those who were new to such events. A characteristic of the feedback, both positive and negative, was the prevalence of social media. For example, the event precipitated various Facebook groups, ${ }^{49}$ which served as a forum for entrants to support each other's training efforts and commiserate with each other over the event's shortcomings. This example comes from Claire Ward, a 2008 entrant, and it appeared on the official Run to the Beat Facebook group page:

The music was the main reason I signed up, and I thought the music was rubbish apart from the Kiss FM stand and one right at the very end!! 50

Were such harsh criticisms of the musical output fair, and if so, what is the explanation? My research team provided an exhaustive variety of playlists and performance directions for the event, for both live and pre-recorded music (DJ stands). Although these playlists were solicited with apparent interest by the event organisers, discussed at length and subsequently refined, they were never used for the live acts. In fact, the music output appeared to be determined entirely at the behest of the City Showcase organisation that provided the majority of the live acts. Rather than play music that was appropriate to the nature of the event, many live acts sought to 'make their statement about the human condition' with dark, 
dowdy, negatively valenced or even frenetic selections. There was no apparent regulation and the young musicians simply performed their chosen material regardless of its tempo or suitability for the runners.

There were some notable exceptions to the otherwise chaotic musical output. For example, London artist Radiola performed the event's theme tune 'Run To The Beat ${ }^{51}$ in 2009, which was composed using a brief that I prepared and distributed to songwriters in an open competition. Grime star Tinie Tempah gave a rousing performance in headlining the 2010 event; his appearance brought a huge number of additional spectators creating a carnival atmosphere around the main stage near the start-finish line. Also, Bhangrainfluenced hip-hop group Panjabi Hit Squad performed a memorable percussion-orientated set at the inaugural 2008 event. The band's lead vocalist used improvisational techniques to interact with the fatiguing runners and provide well-received encouragement in spite of the grim weather.

The performance of the Panjabi Hit Squad underlines the essentially multi-cultural flavour of the event which was also galvanised by the deliberate inclusion of musical idioms that reflected the preferences of varying subcultural groups (i.e., urban and rock music). ${ }^{52}$ Despite some organisational failings, the Run to the Beat event has elicited many positive outcomes. Large sums of money have been raised for a wide range of charities (over $£ 400,000$ for Leukaemia and Lymphoma Research in the first year alone), different strands of the community have been brought together (performing musicians, local residents, charity fundraisers, elite athletes and recreational runners) and London has been afforded a new half marathon, which may provide a more accessible alternative to the its famous counterpart the London Marathon. 


\section{The role of the media}

During my involvement, Run to the Beat was notable for its public face and media engagement. Indeed, perhaps part of the reason for the vehemence of the negative feedback it garnered was the effectiveness of the marketing campaign, which promoted it. It is fair to comment that, from the outset, media partners were considered to be of seminal importance in terms of promoting the event and reaching people who perhaps had never before considered signing up for a mass participation endurance event. The London Evening Standard, London Metro, The Wharf newspaper, Capital Radio, Radio 1, The Docklands newspaper, Heart FM, Athletics Weekly, Runner's World Magazine and Sport Magazine were all heavily involved. The commentary provided by the media is, in many ways, typified by this piece from Simon Hayes:

Olympic athlete Christian Malcolm was banging the drum for the return of a unique race to the streets of Greenwich. The $200 \mathrm{~m}$ sprinter was at The $\mathrm{O} 2$ this morning to help launch the Sony Ericsson Run to the Beat, which takes place in the borough on Sunday, September 27. He said: 'I think it helps motivate you. It's difficult, especially when you are training on your own, you need something to get you going and keep you focussed, to take your mind off the pain, more than anything, when you go through that tough stage. Music does that. For me, I listen to urban music and I find the lyrics keep me focussed, keep me thinking, keep me positive, and I find the beat just physically gets me going. ${ }^{53}$

In hindsight, the most significant part of my role was not music selection but media representation. I gave myriad interviews to the press concerning the event and played an integral role at all launch and promotional events. In this manner, I served as a figurehead for 
the event and, in a way that increasingly characterises the intersection of academic institutions and commercial organisations, I provided a sense of scientific legitimacy to the product. The credulity of the media is voiced here by Claire Soares:

The race was the brainchild of Costas Karageorghis, a sport psychologist at Brunel University. His latest research, due to be published in the US Journal of Sport \& Exercise Psychology, found that when listening to tracks from Madonna to the Red Hot Chili Peppers, most runners found the exercise more pleasurable than usual, even those on the verge of collapsing on the treadmill. In general, they ran further and for longer; some found that their endurance levels were increased by more than 15 per cent. ${ }^{54}$

I have often been encouraged (or required) by commercial partners to wear a white labcoat in my public engagements in connection to their products, even though this laboratory apparel is certainly not reflective of the psychological work I undertake in the music-exercise domain. Nonetheless, the media engagements benefitted me academically as I was able to showcase my new related research each year; there seemed to be an insatiable appetite for this type of output, particularly among health columnists and lifestyle magazine feature writers. This publicity aspect provided an evidence trail for the social and economic impact of my work and also helped to raise its international profile, particularly in North America.

\section{Conclusion}

Run to the Beat is an ambitious concept, which succeeded on some levels - such as enthusing thousands of women to tackle such an event for the first time - while failing on others; the shortcomings of the inaugural 2008 event being the most prominent and widely documented. As a model for the cooperation of the corporate and academic sectors, the event could have 
gone much further. Whereas the organisers were keen to capitalise on the public perceptions of scientific knowledge and integrity, in some instances they were forced to disregard the supposed premise of the event in favour of their commercial and contractual obligations. Nevertheless, Run to the Beat was a particularly successful exercise in knowledge transfer. The media coverage and web presence devoted to the scientific premise behind the event did much to communicate the essence of the work I am involved in to a wider, non-academic audience; there are more than 30,000 web-based citations linking my research with Run to the Beat.

The event was also successful in cultural terms, bringing together diverse strands of the community and uniting them in a common goal and a shared love of music and physical activity. When seen through a cultural prism, even the organisational failures may not have been so undesirable, as they brought the participants together by giving them a common enemy. The postscript is that the event looks set to continue in the near future and the 20112012 races appear to have been marked by considerably better organisation. It may transpire that Run to the Beat will truly fulfil its remit of being a multicultural, accessible mass participation event defined by a unique intersection of running and motivational music: an incarnation of the principle I have researched for the past two decades. 


\section{References}

Atkinson, G., Wilson, D., and Eubank, M., 'Effects of music on work-rate distribution during a cycling time trial'. International Journal of Sports Medicine 25 (2004): 611-15.

Bacon, C. J, Myers, T. R., and Karageorghis, C. I., 'Effect of music-movement synchrony on exercise oxygen consumption.’ Journal of Sports Medicine and Physical Fitness 52 (2012): 359-65.

Bharani, A., Sahu, A., and Mathew, V. 'Effect of passive distraction on treadmill exercise test performance in healthy males using music.' International Journal of Cardiology 97 (2004): 305-6.

Bishop, D. T, Karageorghis, C. I., and Loizou, G., 'A grounded theory of young tennis players' use of music.' Journal of Sport \& Exercise Psychology, 29 (2007): 584-607.

Brownley, K. A., McMurray, R. G., and Hackney, A. C., 'Effects of music on physiological and affective response to graded treadmill exercise in trained and untrained runners.' International Journal of Psychophysiology 19 (1995): 193-201.

Crowther, R. D., and Durkin, K., 'Sex- and age-related differences in musical behaviour, interests and attitudes towards music of 232 secondary school students.' Educational Studies 20 (1982): 13-8.

Crust, L., and Clough, P. J., 'The influence of rhythm and personality in the endurance response to motivational asynchronous music.' Journal of Sports Sciences 24 (2006): $87-195$.

Edworthy, J., and Waring, H., 'The effects of music tempo and loudness level on treadmill exercise.' Ergonomics 49 (2006): 1597-610. 
Elliott, D., Carr, S., and Savage, D., 'Effects of motivational music on work output and affective responses during sub-maximal cycling of a standardized perceived intensity.' Journal of Sport Behavior 27 (2004): 134-47.

Hardy, C. J., and Rejeski, W. J., 'Not what, but how one feels: The measurement of affect during exercise.' Journal of Sport \& Exercise Psychology 11 (1989): 304-17.

Iwanaga, I., 'Relationship between heart rate and preference for tempo of music.' Perceptual and Motor Skills 81 (1995a): 435-40.

Iwanaga, I., 'Harmonic relationship between preferred tempi and heart rate'. Perceptual and Motor Skills 81 (1995b): 67-71.

Karageorghis, C. I., Drew, K. M., and Terry, P. C. 'Effects of pretest stimulative and sedative music on grip strength.' Perceptual and Motor Skills 83 (1996): 1347-52.

Karageorghis, C. I., Jones, L., and Low, D. C., 'Relationship between exercise heart rate and music tempo preference.' Research Quarterly for Exercise and Sport 26 (2006): 24050.

Karageorghis, C. I., Jones, L., Priest, D. L., Akers, R. I., Clarke, A., Perry, J. M., Reddick, B. T., Bishop, D. T., and Lim, H. B. T., 'Revisiting the exercise heart rate-music tempo preference relationship.' Research Quarterly for Exercise and Sport 82 (2011): 27484.

Karageorghis, C. I., Jones, L., and Stuart, D. P. 'Psychological effects of music tempi during exercise.' International Journal of Sports Medicine 29 (2008): 613-9.

Karageorghis, C. I., Mouzourides, D., Priest, D. L., Sasso, T., Morrish, D., and Whalley, C. 'Psychophysical and ergogenic effects of synchronous music during treadmill walking.' Journal of Sport \& Exercise Psychology 31 (2009): 18-36. 
Karageorghis, C. I., and Priest, D. L., 'Music in the exercise domain: A review and synthesis (Part I).' International Review of Sport and Exercise Psychology 5 (2012a): 44-66.

Karageorghis, C. I., and Priest, D. L., 'Music in the exercise domain: A review and synthesis (Part II).’ International Review of Sport and Exercise Psychology 5 (2012b): 67-84.

Karageorghis, C. I., Priest, D. L., Terry, P. C., Chatzisarantis, N. L., and Lane, A. M., 'Redesign and initial validation of an instrument to assess the motivational qualities of music in exercise: The Brunel Music Rating Inventory-2.' Journal of Sports Sciences 24 (2006): 899-909.

Karageorghis, C. I., Priest, D. L., Williams, L. S., Hirani, R. M., Lannon, K. M., and Bates, B. J., 'Ergogenic and psychological effects of synchronous music during circuit-type exercise.' Psychology of Sport and Exercise 11 (2010): 551-9.

Karageorghis, C. I., and Terry, P. C., 'The psychophysical effects of music in sport and exercise: A review.' Journal of Sport Behavior 20 (1997): 54-68.

Karageorghis, C. I., and Terry, P. C., 'The psychological, psychophysical and ergogenic effects of music in sport: A review and synthesis'. In Sporting Sounds: Relationships between Sport and Music, edited by A. Bateman and J. Bale, 13-36. Abingdon: Routledge, 2009.

Karageorghis, C. I., and Terry, P. C., Inside Sport Psychology. Champaign, IL: Human Kinetics, 2011.

Karageorghis, C. I., Terry, P. C., and Lane, A. M. 'Development and initial validation of an instrument to assess the motivational qualities of music in exercise and sport: The Brunel Music Rating Inventory.' Journal of Sports Sciences 17 (1999): 713-24.

Macone, D., Baldari, C., Zelli, A., and Guidetti, L., 'Music and physical activity in psychological well-being.' Perceptual and Motor Skills 103 (2006): 285-95. 
Morgan, W. P., and Pollock, M. L., 'Psychologic characterization of the elite distance runner.' Annals of the New York Academy of Sciences 301 (1977): 383-403.

Nethery, V. M. 'Competition between internal and external sources of information during exercise: Influence on RPE and the impact of the exercise load.' Journal of Sports Medicine and Physical Fitness 42 (2002): 172-8.

North, A. C., and Hargreaves, D. J., 'Music and taste'. In The Social and Applied Psychology of Music, edited by A. C. North, and D. J. Hargreaves, 75-142. Oxford: Oxford University Press. 2008.

Priest, D. L., and Karageorghis, C. I., 'A qualitative investigation into the characteristics and effects of music accompanying exercise.' European Physical Education Review 14 (2008): 347-66.

Priest, D. L., Karageorghis, C. I., and Sharp, N. C. C. 'The characteristics and effects of motivational music in exercise settings: The possible influence of gender, age, frequency of attendance, and time of attendance.' Journal of Sports Medicine and Physical Fitness 44 (2004): 77-86.

Rejeski, W. J. 'Perceived exertion: An active or passive process?' Journal of Sport Psychology 75 (1985): 371-8.

Razon, S., Basevitch, I., Land, W., Thompson, B., and Tenenbaum, G., 'Perception of exertion and attention allocation as a function of visual and auditory conditions.' Psychology of Sport and Exercise 10 (2009): 636-43.

Schwartz, S. E., Fernhall, B., and Plowman, S. A., 'Effects of music on exercise performance.' Journal of Cardiopulmonary Rehabilitation 10 (1990): 312-6. 
Shen, B., Chen, A., Scrabis, K., and Tolley, H. 'Gender and interest-based motivation in learning dance.' Journal of Teaching in Physical Education 22 (2003): 396-409.

Simpson, S. D., and Karageorghis, C. I., 'The effects of synchronous music on 400-m sprint performance.' Journal of Sports Sciences 24 (2006): 1095-102.

Szabo, A., Small, A., and Leigh, M. 'The effects of slow- and fast-rhythm classical music on progressive cycling to voluntary physical volitional exhaustion.' Journal of Sports Medicine and Physical Fitness 39 (1999): 220-5.

Szmedra, L., and Bacharach, D. W. 'Effect of music on perceived exertion, plasma lactate, norepinephrine and cardiovascular hemodynamics during treadmill running.' International Journal of Sports Medicine 19 (1998): 32-7.

Tenenbaum, G. 'A social-cognitive perspective of perceived exertion and exertion tolerance.' In Handbook of Sport Psychology, edited by R. N. Singer, H. A. Hausenblas, and C. Janelle, 810-22. New York: Wiley, 2001.

Terry, P. C., and Karageorghis, C. I., 'Psychophysical effects of music in sport and exercise: An update on theory, research and application.' In Katsikitis, M. ed. Proceedings of the 2006 Joint Conference of the APS and the NZPS. Melbourne, VIC: Australian Psychological Society, 2006, 415-9.

Terry, P. C., and Karageorghis, C. I., 'Music in sport and exercise'. In The New Sport and Exercise Psychology Companion, edited by T. Morris, and P. C Terry, 359-80. Morgantown, WV: Fitness Information Technology, 2011.

Terry, P. C., Karageorghis, C. I., Mecozzi Saha, A, and D’Auria, S. 'Effects of synchronous music on treadmill running among elite triathletes.' Journal of Science and Medicine in Sport 15 (2012): 52-7. 
Yamashita, S., Iwai, K., Akimoto, T., Sugawara, J., and Kono, I., 'Effects of music during exercise on RPE, heart rate and the autonomic nervous system'. Journal of Sports Medicine and Physical Fitness 46 (2006): 425-30. 


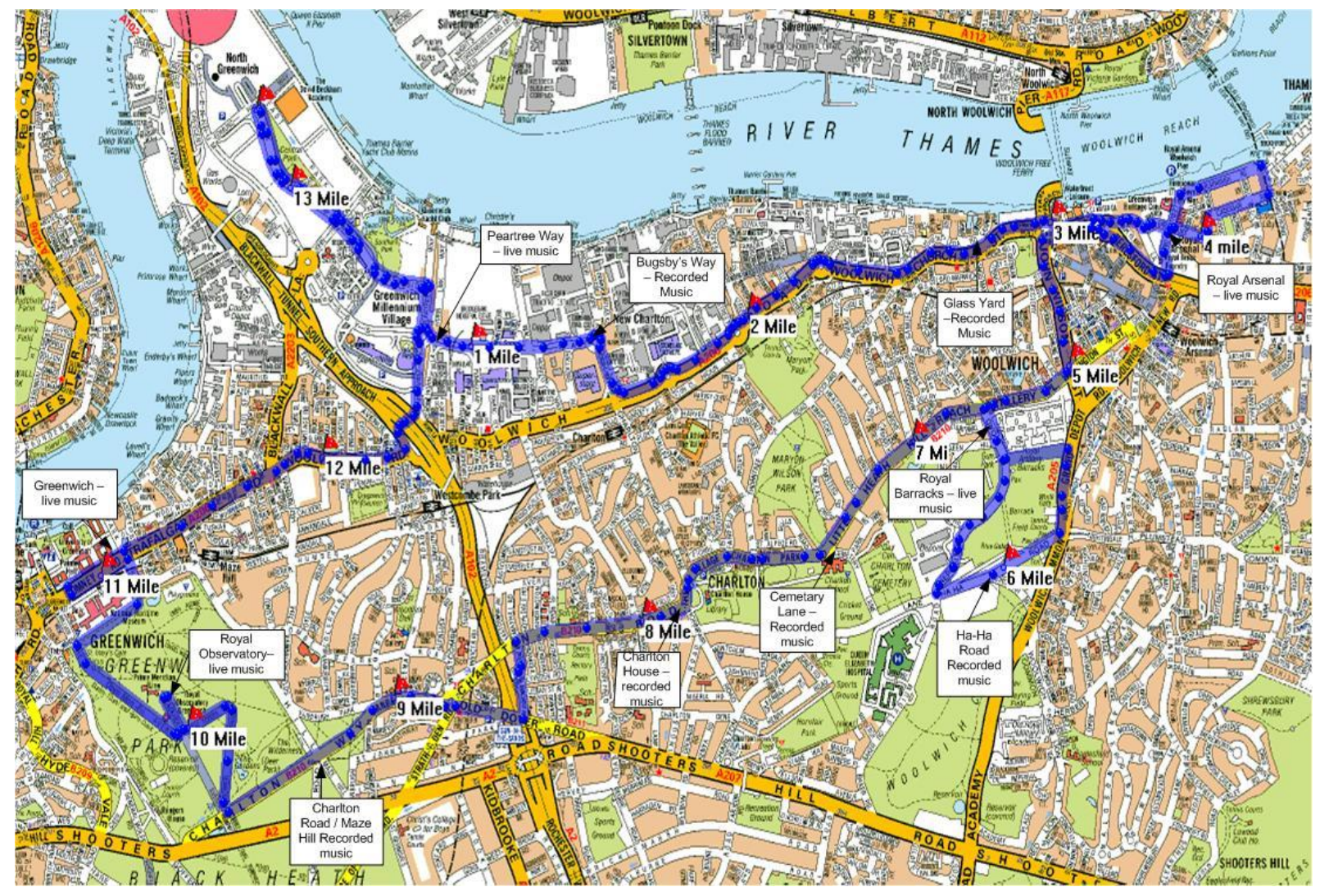

Figure 1: Routemap of the 2009 London Run to the Beat event (reproduced with permission from International Management Group Mass Participation Sport). 



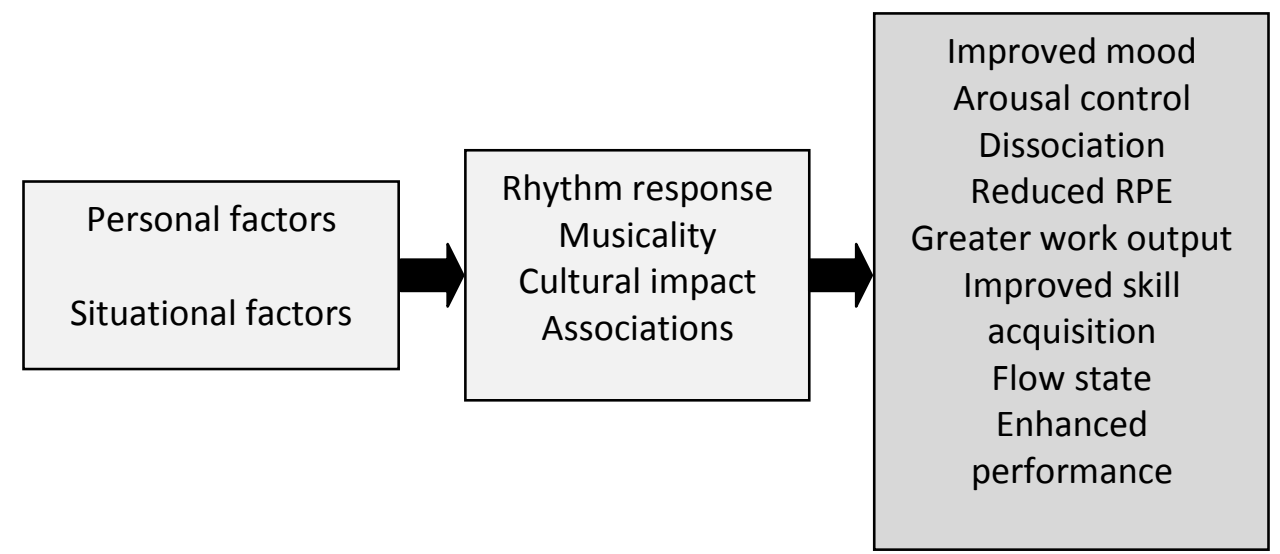

Figure 2: Conceptual framework for benefits of music in sport and exercise contexts (reproduced with permission from the Australian Psychological Society; 2006, Proceedings of the Joint Conference of the Australian Psychological Society and the New Zealand Psychological Society, 415-419). 


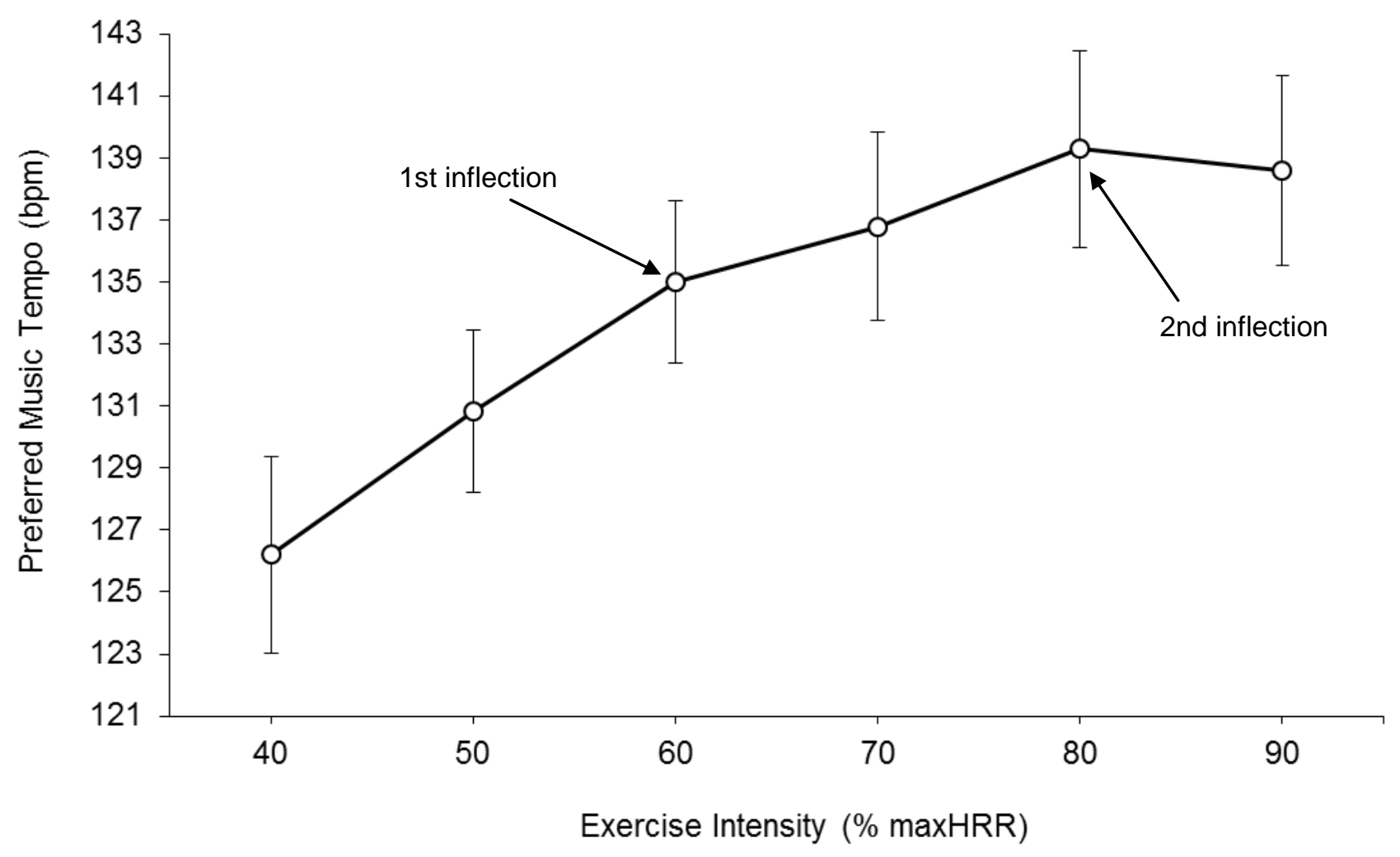

Figure 3: Observed cubic relationship between preference for music tempo and exercise intensity (reproduced with permission from American Alliance for Health, Physical Education, Recreation, and Dance; 2011, Research Quarterly for Exercise and Sport, 82(2), 281). 


\section{Notes}

${ }^{1}$ Run to the Beat marketing slogan, 2008.

${ }^{2}$ British Association of Sport and Exercise Sciences expert statement on the use of music in exercise, 2011: http://www.bases.org.uk/write/Documents/SES_EXPERT_3.pdf.

${ }^{3}$ Rule 144.3(b) of USA Track and Field Manual.

${ }^{4}$ The quote regarding the New York Marathon is from The Times, November 2, 2007.

${ }^{5}$ Examples of the coverage include The Telegraph, January 12, 2008; The Sunday Times, November 2, 2007.

${ }^{6}$ www.nytimes.com/2008/01/10/fashion/10fitness.html (accessed October 17, 2011).

${ }^{7}$ www.run2rhythm.com (accessed October 17, 2011).

${ }^{8}$ www.runtothebeat.co.uk (accessed October 17, 2011).

${ }^{9}$ The definition of motivational music is taken from Karageorghis, Terry, and Lane, 'Development and Initial Validation'.

${ }^{10}$ The expanded list appears in Terry and Karageorghis, 'Music in Sport and Exercise'.

${ }^{11}$ The development of the BMRI was covered in Karageorghis, Terry, and Lane, 'Development and Initial Validation'.

${ }^{12}$ The redevelopment of the BMRI was covered in Karageorghis et al., 'Redesign and Initial Validation'.

${ }^{13}$ The criteria were taken from Terry and Karageorghis, 2006; Karageorghis and Terry, Inside Sport Psychology; Karageorghis, Terry, and Lane, 'Development and Initial Validation'; Karageorghis et al., 'Revisiting the Exercise Heart Rate'.

${ }^{14}$ www.run247.com/articles/article-43-run-to-the-beat-preview.html (accessed October 26, 2011).

${ }^{15}$ The survey-based study is Priest, Karageorghis, and Sharp, 'Characteristics and Effects of Motivational Music'.

${ }^{16}$ The 'battle of the genres' strategy: www.flavourmag.co.uk/sony-ericsson-run-to-the-beat-2009/ (accessed October 26, 2011).

${ }^{17}$ For music lowering perceptions of exertion, see Bharani et al., 'Effects of Passive Distraction'; Karageorghis and Priest, 'Music in the Exercise Domain (Part I)'; Karageorghis and Priest, 'Music in the exercise domain (Part II); Nethery, 'Competition between Internal and External Sources'; Szmedra and Bacharach, 'Effects of Music'.

${ }^{18}$ For the dominance of fatigue-related feedback at high exercise intensities, see Rejeski, 'Perceived Exertion'; Tenenbaum, 'A Social-Cognitive Perspective'.

${ }^{19}$ Karageorghis et al., 'Pyschophysical and Ergogenic Effects.'

${ }^{20}$ The Feeling Scale was developed by Hardy and Rejeski, 'Not What, But How One Feels'.

${ }^{21}$ On music use to regulate arousal, see Bishop et al., 'A Grounded Theory'; Priest and Karageorghis, 'A Qualitative Investigation'. 
${ }^{22}$ For pre-task music aiding strength-related task, see Karageorghis et al., 'Effects of Pretest Stimulative and Sedative Music'.

${ }^{23}$ For pre-task music aiding muscular endurance task, see Crust and Clough, 'The Influence of Rhythm'.

${ }^{24}$ For discussions of exercise heart rate and music-tempo preferences, see Karageorghis, Jones et al., 'Relationship between Exercise Heart Rate and Music Tempo Preference'.; Karageorghis et al., 'Psychological Effects of Music Tempi'; and Karageorghis et al., 'Revisiting the Exercise Heart Rate'; Karageorghis and Terry, 'The Psychological, Psychophysical, and Ergogenic Effects'.

${ }^{25}$ For previous work on music-tempo preference and heart rate, see Iwanaga, 'Relationship between Heart Rate and Preference; Iwanaga, 'Harmonic Relationship between Preferred Tempi and Heart Rate'.

${ }^{26}$ For the two inflection points, see Karageorghis et al., 'Revisiting the Exercise Heart Rate'.

${ }^{27}$ For the manipulation of musical tempo, see Edworthy and Waring, 'Effects of Music Tempo'; Karageorghis and Terry, 'The psychophysical effects of music in sport and exercise'.

${ }^{28}$ For increased work-output from listening to synchronous music, see Karageorghis and Priest, 'Music in the Exercise Domain (Part I)'; Karageorghis and Priest, 'Music in the Exercise Domain (Part II)'.

${ }^{29}$ For running with synchronous music, see Simpson and Karageorghis, 'The Effects of Synchronous Music'; Terry et al., 'Effects of Synchronous Music'.

${ }^{30}$ For musical tempo regulating performance, see Edworthy and Waring, 'Effects of Music Tempo'.

${ }^{31}$ For a $15 \%$ increase in endurance, see Karageorghis et al., 'Psychophysical and Ergogenic Effects'.

${ }^{32}$ For music and cycling efficiency, see Bacon et al., 'Effects of Music-Movement Synchrony'.

${ }^{33}$ For increase in strength output, see Crust and Clough 'Influence of Rhythm'; Razon et al., 'Perception of Exertion'.

${ }^{34}$ For increase in aerobic endurance, see Atkinson et al., 'Effects of Music'; Elliott et al., 'Effects of Motivational Music'.

${ }^{35}$ For increase in work-rate, see Elliott et al., 'Effects of Motivational Music'; Szabo et al., 'Effects of Slowand Fast-Rhythm Classical Music'.

${ }^{36}$ For women's exposure to dance music, see Crowther and Durkin, 'Sex- and Age-Related Differences'.

${ }^{37}$ For women's desire to dance, see Shen et al., 'Gender and Interest-Based Motivation'.

${ }^{38}$ For gender differences in rhythm response, see Karageorghis et al., 'Psychophysical and Ergogenic Effects'.

${ }^{39}$ For men deriving less benefit from synchronous music than women, see Karageorghis et al., 'Ergogenic and Psychological Effects'.

${ }^{40}$ For women's endurance with musical accompaniment, see Macone et al., 'Music and Physical Activity'; Schwartz et al., 'Effects of Music on Exercise'.

${ }^{41}$ For qualitative work on this, see Priest et al., 'Characteristics and Effects of Motivational Music'.

${ }^{42}$ Runner entry statistics can be found on www.challengerworld.com/results/run-to-the-beat.aspx.

${ }^{43}$ John McFarlane's quote is on 8lane Forum, September 28, 2009. 


\footnotetext{
${ }^{44}$ Morgan and Pollock, 'Psychologic Characterization' researched attentional style of elite distance runners.

${ }^{45}$ Brownley et al., 'Effects of Music' covered the difference in music appreciation by elite and non-elite exercisers.

${ }^{46}$ Claire Soares' article appeared in The Independent, October 7, 2008.

${ }^{47}$ Nerina's message appeared on the following page:

www.runnersworld.co.uk/forum/forummessages.asp?UTN=120787 \&URN=6\&SP=\&V=2\&searchdate $=0 \& \mathrm{cp}=9$ $\& \mathrm{dt}=4$ (accessed October 24, 2011).

${ }^{48}$ www.runnersworld.co.uk/forum/forummessages.asp?URN=1\&UTN=165914\&SP=\&V=6 (accessed October 24, 2011).

${ }^{49}$ Examples of Facebook groups: http://www.facebook.com/pages/Run-To-The-Beat-HalfMarathon/140550409312536; http://en-gb.facebook.com/event.php?eid=351635733253; http://engb.facebook.com/event.php?eid=71554795518 (accessed October 24, 2011).

${ }^{50}$ http://www.facebook.com/runtothebeat (accessed October 28, 2011).

${ }^{51}$ Run to the Beat theme tune: www.youtube.com/watch?v=IQOcIVe2uo4 (accessed October 28, 2011).

${ }^{52}$ For a discussion of music preference and subculture, consult North and Hargreaves, 'Music and Taste'.

${ }^{53}$ Simon Hayes' piece appeared on the page http://www.wharf.co.uk/2009/02/run-to-the-beat-up-andrunning.html (February 11, 2009).

${ }^{54}$ Claire Soares' comment was taken from her article in The Independent, October 7, 2008.
} 